\title{
Human Pluripotent Stem Cell Therapy for Huntington's Disease: Technical, Immunological, and Safety Challenges
}

\author{
Camille Nicoleau • Pedro Viegas • Marc Peschanski • \\ Anselme L. Perrier
}

Published online: 6 October 2011

(C) The American Society for Experimental NeuroTherapeutics, Inc. 2011

\begin{abstract}
Intra-striatal transplantation of homotypic fetal tissue at the time of peak striatal neurogenesis can provide some functional benefit to patients suffering from Huntington's disease. Currently, the only approach shown to slow down the course of this condition is replacement of the neurons primarily targeted in this disorder, although it has been transient and has only worked with a limited number of patients. Otherwise, this dominantly inherited neurodegenerative disease inevitably results in the progressive decline of motricity, cognition, and behavior, and leads to death within 15 to 20 years of onset. However, fetal neural cell therapy of Huntington's disease, as with a similar approach in Parkinson's disease, is marred with both technical and biological hurdles related to the source of grafting material. This heavily restricts the number of patients who can be treated. A substitute cell source is therefore needed, but must perform at least as well as fetal neural graft in terms of brain recovery and reconstruction, while overcoming its major obstacles. Human pluripotent stem cells (embryonic in origin or induced from adult cells through genetic reprogramming) have the potential to meet those challenges. In this review, the therapeutic potential in view of 4 major issues is identified during fetal cell therapy clinical trials: 1 )
\end{abstract}

Camille Nicoleau and Pedro Viegas contributed equally to the work.

Electronic supplementary material The online version of this article (doi:10.1007/s13311-011-0079-4) contains supplementary material, which is available to authorized users.

C. Nicoleau $\cdot$ P. Viegas $\cdot$ M. Peschanski $\cdot$ A. L. Perrier $(\triangle)$ INSERM U861, I-STEM, AFM,

Evry Cedex 91030, France

e-mail: aperrier@istem.fr

C. Nicoleau $\cdot$ P. Viegas $\cdot$ M. Peschanski $\cdot$ A. L. Perrier

UEVE U861, I-STEM, AFM,

Evry Cedex 91030, France logistics of graft procurement, 2) quality control of the cell preparation, 3) immunogenicity of the graft, and 4) safety of the procedure.

Keywords Huntington's disease - Cell therapy · Pluripotent stem cells · Induced pluripotent stem cells $\cdot$ Embryonic stem cells $\cdot$ Transplantation $\cdot$ Neural stem cells

\section{Introduction}

For the past decade, clinical trials have provided evidence of the some benefit of fetal neural transplantation in Huntington's disease (HD). Presently, this surgical approach is the only therapeutic strategy that has demonstrated symptomatic improvements in HD patients. HD is a devastating genetic disorder, caused by the mutation of the Huntingtin (HTT) gene [1], which typically features neuronal degeneration, especially severe for $\gamma$-aminobutyric acid (GABA) medium-spiny neurons (MSN) of the caudate nucleus and the putamen, in the striatum. As the disease progresses, several other cortical and subcortical regions are affected. Motor, cognitive, and psychiatric impairments (the major symptoms of HD) usually begin in adulthood and reflect the profile of striatal neuronal loss and cortical dysfunction. On average, HD patients die within 17 years of clinical onset. Three decades of experimental work have demonstrated that transplantation of fetal striatal neural cells was effective for the reconstruction and recovery of rodent and even nonhuman primates with drug-induced striatal lesions [2-4]. Successes in experimental cell therapy have led to a similar surgical approach being clinically tested in humans [5-10]. Although a larger version of those early phase I/II open-label clinic trials is still ongoing, at least some of the completed 
trials resulted in significant and long-lasting functional benefits $[5,6,11]$.

Positive clinical results were unfortunately tampered by major logistical and biological hurdles regarding the procurement, quality control, and delay before the use of the neuroblasts harvested from the terminated fetus. In practice, this has heavily restricted the number of patients eligible for this therapy. Consequently, identification of alternative cell sources and the active exploration of their therapeutic potential have been actively conducted for the past decade in parallel to ongoing clinical trials. Primary fetal cells derived from ganglionic eminences (GE) at 7 to 10 weeks postconception provide a current clinical standard [2] for the extent of repair and symptomatic improvements that regenerative medicine can achieve in HD patients. The challenge of any alternative source of graft for HD will be to overcome fetal neural cell therapy roadblocks while still matching or possibly exceeding this standard. Many alternative sources of cells have been considered, including xenografts, immortalized human fetal neural cells, and various neural stem cells (for more detail see Dunnett and Rosser [12]). However, since the first generation of human embryonic stem cells (hESCs) by James Thomson [13] and collaborators, and the more recent but no less groundbreaking discovery of human somatic stem cell reprogramming into induced pluripotent stem cells (iPSCs) by Shinya Yamanaka (for more details see Takahashi et al. [14] and Yu et al. [15]), the field of regenerative medicine has mainly focused its attention on the use of human pluripotent stem cells (hPSCs) as grafting material. For HD cell therapy, as with many other degenerative diseases, hPSC derivatives, at the moment, are without much contest the most promising candidates for cell replacement strategies.

In this review, we summarize and discuss the 4 major hurdles encountered by fetal neural cell replacement for HD, namely 1) logistics, 2) quality control, 3) immunogenicity, and 4) safety. In parallel, we review what might be achieved using human pluripotent stem cells, with particular respect to these hurdles and what newer issues have arisen that are specific to the potential use of hPSC derivatives.

\section{Supplying Graft for HD Cell Therapy: The Devil is in the Logistics}

Decades of experimental cell replacement using mostly rodents with excitotoxic striatal lesions have determined what type of fetal neural tissue works best to repair and reconstruct a lesioned striatum. The most relevant graft for striatal repair should differentiate into all normal populations of striatal neurons, in particular, but not exclusively into the DARPP32+ medium spiny projection neurons that are selectively targeted in HD during the early stages of the disease. Not surprisingly, such a graft is best generated from homotypic tissue (harvested from the region of the embryonic brain where these relevant neurons are born). The optimal stage of the harvest is just at the peak time of neurogenesis of the DARPP32+ cell population. The caudate and putamen develop from the lateral part of the ganglionic eminences in the ventral telencephalon. Projection striatal neurons generation peaks at 8 to 14 weeks postconception in the human (E15 in rat) [2]. The optimal tissue and donor age was thus estimated as GE tissue from 8- to 9-week-old donors, taking into account both the legal time window of elective abortions in various countries, and the technical difficulty raised by fetus retrieval at an older age $[16,17]$. Overall, in nearly all clinical trials, 7 - to 10week-old fetuses have been used [5-10]. Qualitatively, GE graft-derived neurons must re-establish extensive synaptic connectivity with their proper targets in the host brain, as well as be properly targeted by orphan axonal terminals of the host brain (demonstrated in the rat [18]). Although brain repair is far from perfect, function of such grafts has been demonstrated in rats by recovery in a wide range of motor and cognitive behavioral tests. This function is highly dependent on the integrity of striatal neural networks, in particular the fronto-striatal circuitry $[19,20]$. In the few transplanted patients autopsied, histological analyses at 18 months [21] to 10 years [9, 22] after transplantation have provided both qualitative and quantitative measurement of cellular biology outcome of therapeutic fetal grafts. Human fetal grafts in these patients are rather small, representing no more than $\sim 4 \%$ of the corpus striatum volume and contain less than $60 \%$ of P-zones (i.e., region selectively positive for striatal interneurons or for striatal projection neurons markers [22]. These graft-derived Pzones are specifically surrounded by activated microglia, whereas MSNs inside these regions are found more markedly positive for apoptotic markers. Nonetheless, host-derived fibers $(\mathrm{TH}+)$ outgrowth within the graft, glutamatergic axonal varicosities opposed to MSNs and synaptic contacts by transplanted neurons are detected.

Quantitative requirements of grafting material for HD are much less well-defined. Availability of rat fetal cells is not a limiting factor and transplantation of a reduced number of striatal fetal neuroblasts was not extensively tested. In the context of clinical application, however, quantitative requirement becomes much more critical as the number of cells harvested from a single fetus is just enough or even suboptimal for the transplantation in a single hemisphere of an HD patient. Added to this constraint are the significant rate of termination cancellations or postponements and the loss of embryos due to structural damage precluding precise dissection of the GE. In the end, the sum of all these constraints results in a major problem of reliability of the timely supply of 
even a single GE preparation per day to the surgeon. Overall, the rate of cancellation of surgery has often been high and quite variable in the ongoing multi-center phase II European study, ranging from almost nothing in 1 transplantation center to around half of the time in many others. This cancellation cascade additionally leads to major problems regarding the management of patients (already prone to depression) who are eagerly expecting their transplantation.

Early on, creation of banks of striatal neuroblasts ready to be used by the surgeons was considered. In this direction, the first barrier, namely the amplification of striatal progenitors without losing their therapeutic potential for the HD patient, however, has never been overcome. Cells harvested from the embryonic brain at 7 to 10 weeks postconception, including those from the GE, can indeed be amplified as neurospheres in presence of mitogens (e.g., FGF2). Unfortunately, up to now, none of the tested conditions has allowed striatal progenitors to keep their regional commitment (for more detail see Hauser et al. [12]). As shown by several groups, long-term expansion (i.e., usually at 4 to 6 weeks) of rodent or human GE tissue failed to produce cells capable of generating in vivo the complement of striatal neurons expected, in particular the DARPP32+ neurons [23-27]. The only apparent exception was the work by Armstrong and colleagues [28] who demonstrated that expanded GE-derived fetal neural progenitors can generate human cells still capable of maturing into DARPP32+ neurons and massively outgrowing fibers in a lesioned rat striatum. The expansion, however, was only carried out for a very short period of time ( 9 days), thus resulting in a very limited increase in the number of neural cells of interest. Alternatively, immortalization of human GE cells has been tested and was successful in generating self-renewable populations of cells still capable of generating DARPP32+ neurons in vitro [29]. Such cell line or similar lines derived from human fetal telencephalon have not yet proven their capacity to generate striatal neurons in vivo, and thus their likely relevance to HD. However, safety and regulatory hurdles related to their possible clinical application for HD would be straightforward, as the 3 companies involved (ReNeuron, NeuralStem, and Stem cell Inc.) have received approval from relevant national regulatory agencies to use fetal stem cell-based products for neurodegenerative disease, and even demonstrated 1-year survival and safety in humans.

With regard to logistics of HD graft supply, the potential use of hPSC derivatives, instead of fetal neural tissues, constitutes an entirely different paradigm. In contrary to GE fetal preparations, amplification is not an issue for hPSC derivatives, whereas the degree of commitment and purity that can actually be achieved is problematic. The most important (nonmalignant) types of human pluripotent stem cells are hESCs, which were first derived in 1998 from human blastocytes created through in vitro fertilization [13], and human (iPSCs), which were first generated in 2007 from somatic cells of either embryonic, fetal, or adult origin that were genetically reprogrammed to an embryonic stem cell-like state [14, 15]. The 2 defining attributes of these cells are their capacity at long-term self-renewal and their pluripotency. hPSCs are intrinsically able to divide in culture indefinitely without transformation, and thus offer an unlimited supply of starting material for graft production, compatible with much needed extensive quality control and banking of graft preparation. The second attribute of hPSCs is their ability to differentiate into all derivatives of the 3 primary germ layers, allowing the generation of any cell phenotype of the organism, including, in theory, cells equivalent to the progenitors found in 8 to 9-week postconception GE, the current clinical standard of the graft for HD. In practice, the major issue with hPSC is the development of clinical grade protocols that can direct the differentiation of hPSC into GE- or even lateral ganglionic eminence-like (LGE) progenitors. As previously explained, such cells must perform equally or better than fetal GE neural cells. It is important to note, that although differentiation into bona fide MSNs is therapeutically relevant, requirement for other striatal cellular constituents, such as striatal interneurons, striatal glial cells, or even cortical cells might be necessary to allow a striatal graft to integrate and ultimately repair a lesioned striatum. Concerning the generation of therapeutically relevant hPSC derivative for $\mathrm{HD}$, both the development of in vitro protocol for directed differentiation and the identification of the "target cellular population" this protocol must produce are challenging. From a practical point of view, as with many differentiation protocols, the general aim is to recapitulate in vitro human fetal development from blastocyst-like hPSCs up to the specific and committed neuron precursors of the desired region. Control of the efficacy of each step of these protocols usually relies on the identification of region and stage specific marker genes, usually transcription factors, which are key determinants of brain development (Fig. 1). Pluripotent stem cell (PSC) derivatives equivalent to cells located more dorsally (Pax6, Emx1/2, or Tbr1-positive cells) or ventrally (Nkx2.1positive cells) than LGE cells during development (Fig. 1a) can pollute striatal progenitors culture in vitro. Challenges in the use of hPSC derivatives will consist of developing the appropriate directed differentiation protocol and define the proportion of specific phenotypes that will give the best therapeutic outcome, whether it will consist or not of pure MSN progenitors population or more likely of mix striatal or even non-striatal populations.

Neuroectoderm specification, the phase during which the central nervous system is formed from a fraction of the ectoderm, begins with the "neural induction" of ectodermal 

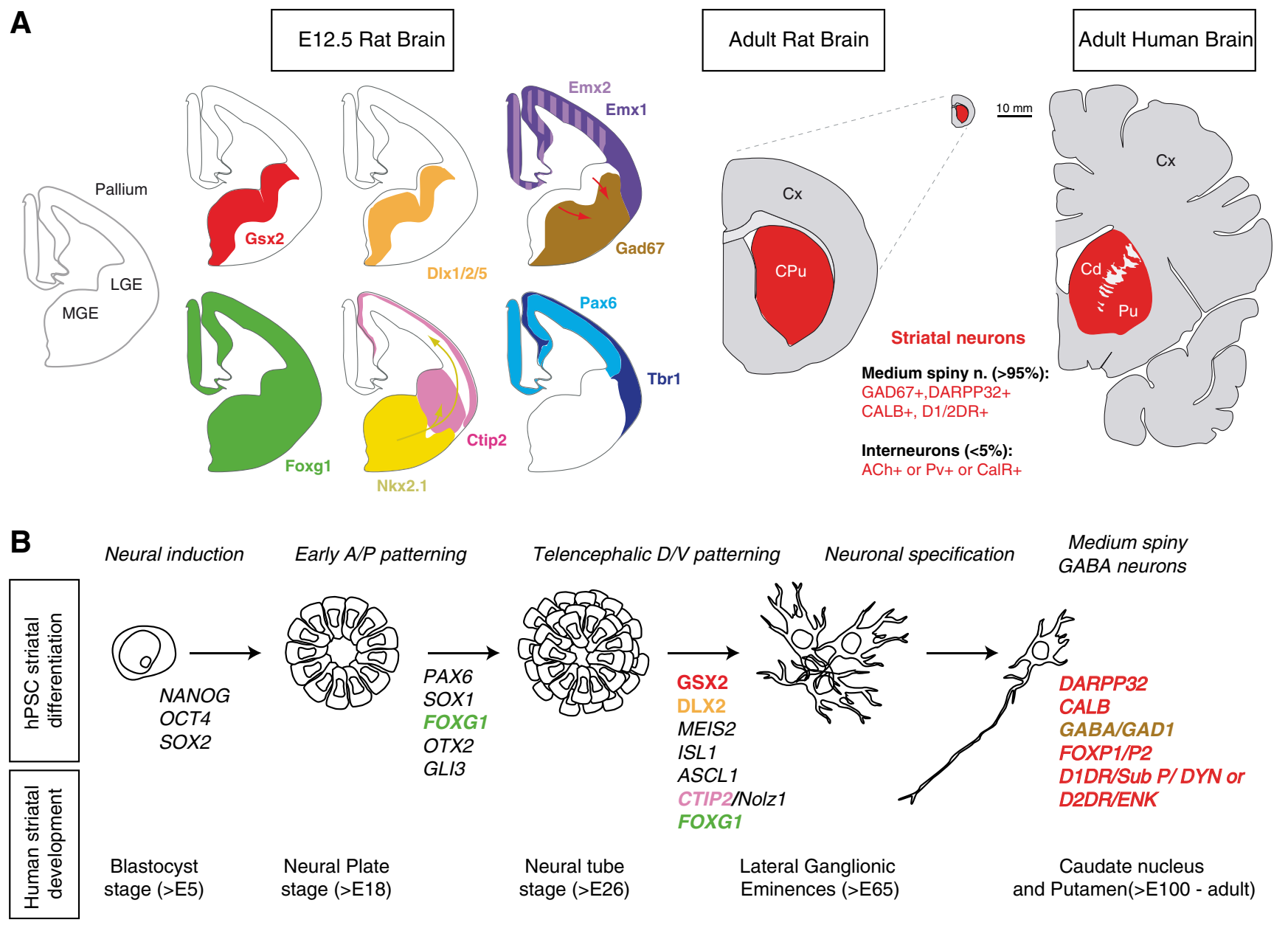

Fig. 1 Recapitulation of human embryonic development of the striatum by human pluripotent stem cells. Diagrams of cross sections of half a rat fetal forebrain (E12.5) and rat or human adult brain shown to scale (a zoom in on the rat section is provided for legibility). In rodents, the striatum arises from the lateral ganglionic eminence (LGE) and the medial ganglionic eminence (MGE) of the ventral telencephalon (FOXG1+) while the cortex arises from the more dorsal telencephalic region (Pallium). Medium spiny GABA neurons (MSN) progenitors express Gsx2, Dlx2 and Ctip2. Striatal and cortical interneuron progenitors express $\mathrm{Nkx} 2.1$ and migrate tangentially from

cells to form the neural plate. Subsequently, the neural plate folds in upon itself (primary neurulation) to form the neural tube, the anterior part of which eventually forms the brain. Several transcription factors are involved in neuroectoderm specification, including zinc finger proteins, Sox family members (in particular SOX1 and SOX2), Otx family members, and helix-loop-helix transcription factors [3032]. Specifically in human development, PAX6 isoforms are key transcriptional determinants of the neuroectoderm, controlling the transition from pluripotency to the neuroectodermal fate [33]. Later, the telencephalic primordium is specified when expression of FOXG1 is initiated by FGF8 signals $[34,35]$. FOXG1 expression in the telencephalon is maintained throughout development and into adulthood. the MGE to lateral and dorsal regions. More than $95 \%$ of the neurons in the adult caudate $(\mathrm{Cd})$ and putamen $(\mathrm{Pu})(\mathrm{CPu}$, in rat) are MSN. Data to generate panel (a) were derived from Watanabe et al. [65], Danjo et al. [67], and Zhao et al. [136] (b) Main steps of human striatal neural ontogenesis presented in parallel with a schematic representation of human pluripotent stem cells (hPSCs) striatal differentiation into medium spiny $\gamma$-aminobutyric acid (GABA) projection neurons for each stages of the corresponding key marker genes

The cortex arises from the dorsal (pallium) part of the telencephalon that expresses Pax6, Emx1/2, and Tbr1 [36]. To the opposite, the striatum arises from the LGE located in ventral telencephalic territories (Fig. 1a). Key transcription factors in the developing striatum include DLX1, DLX2, and more specifically GSX2 (GSH2) [37-39]. Most notably, medium spiny neurons, the most abundant population of neurons in the striatum and the most vulnerable in HD are derived from DLX2-positive progenitors in the germinal zone of the LGE. GSX2 is required for normal LGE development [40]; GSX2 ventralizes pallial progenitors and promotes LGE fate specification at early stages (E9-E11) (for more detail see Jain et al. [41]). The LGE is the major source of MSN [42, 43], which highly express 
DARPP32, an essential modulator of dopamine [44, 45]. MSN also particularly expresses CTIP2 (BCL11B), a transcription factor shown to control their differentiation [46], and FOXP1/2, a transcription factor which colocalizes with CTIP2 [46] and is expressed in the projection neurons but not interneurons of the adult striatum [47, 48]. Postmitotic MSN synthesize GABA from glutamate by the L-glutamic acid decarboxylase (GAD1) and express either dopamine D1 receptors, Substance P and dynorphin, or the dopamine D2 receptor and enkephalin. Some MSN also express calbindin. Each subtype encompasses approximately half of all MSN. Nkx2.1-positive cells in the developing medial ganglionic eminence located in the most ventral telencephalic territories, tangentially migrate (Fig. 1a) to become striatal and cortical interneurons. These interneurons in the human can express acetylcholinesterase, Nicotinamide adenine denucleotide phosphate diaphorase (NADPH-d), parvalbumin, calretinin, nitric oxide synthase 1, or neuropeptide Y [49].

All these developmental marker genes are milestones of quality control for the striatal differentiation of hPSCs (Fig. 1). Since 1998, literally hundreds of publications have described ways to generate in vitro neural cells, first from hESCs and later from human iPSCs. Pioneer protocols [50, 51] yielded a significant numbers of neural cells, the clustering of which, in adherent culture conditions, reminded Zhang et al. [50] of neural tube sections that led them to coin the term "rosettes." Current methods for the neural conversion of hPSC can be grouped into 3 main categories they rely on: 1) Formation of multi-cellular aggregates termed embryoid bodies generated in serum or serum replacement-containing medium [50, 52, 53], 2) neuron-inducing stromal feeder cell co-culture [54-56], and 3) selective survival combined or not with neuroectoderm specification activators and pluripotency inhibitors, such as SMAD inhibitors [52, 57-63].

Concerning the specific differentiation of hPSC-derived neuroepitelial cells (also called Rosette-neural stem cells [R-NSCs]) into striatal neurons precursors, only few protocols have been published (see list of protocols in Table 1). The first conclusive attempt to generate a striatal graft from mouse PSC was reported in 1996 by Dinsmore et al. [64] who demonstrated differentiation of mouse embryonic stem cells (ESC)-derived neural cells into GABAergic neurons after grafting into the quinolinic acid-lesioned rat striatum [64]. Striatal commitment was minimally defined and was only supported by acetylcholinesterase expression. Induction of precise ventral forebrain commitment in PSC derivatives was then described by Sasai and collaborators in 2005 from mouse ESCs and in 2007 from hESCs [65, 66]. The same authors demonstrated subpallial specification (Nkx2.1+ cells) of hESC-derived naive telencephalic progenitors $(\mathrm{FOXG1+})$, and more recently that specification of mouse ESC-derived telencephalic neuroectoderm is dose-dependent, directed by Sonic hedgehog ( $\mathrm{SHH}$ ) signaling with early, but mild treatment with SHH critical for efficient generating LGE progenitors [67]. Although reduction of motor symptoms in the quinolinic acid-lesioned rat transplanted with telencephalic progenitors was reported in the absence of DARPP-32 expression within the graft [68], experimental work with fetal neural cells has clearly established that clinical efficacy is dependent on the appropriate differentiation into MSN and their functional integration in the host brain. The first report of PSC-derived striatal neurons (DARPP32+/FOXG1+) in vivo resulted from the contamination of monkey ESC-derived preparation of ventral midbrain precursors with ventral telencephalic cells. This graft, in a rat model of Parkinson's disease, exhibited DARPP32+/FOXG1+ striatal neurons [69], in addition to the expected dopaminergic neurons. In 2008, our group published a protocol to direct the differentiation of hESC into neurons that exhibit phenotypic features of the medium spiny GABAergic neurons of the striatum both in vitro and in vivo following xenografting in a HD rodent model [70]. Then we observed that our population enriched in striatal progenitors, in addition to yielding significant number of DARPP32+ cells, massively overgrew in vivo to an extent incompatible with their potential use in experimental cell therapy in which the efficacy of the graft would have to be tested. Since then, we have adapted this protocol to monkey ESCs and iPSCs, and we have modified early differentiation steps to use the latest techniques of neural induction-based on a dual SMAD inhibition [62, 63]. In parallel, $\mathrm{Li}$ et al [71] presented modifications of our protocol using a feeder-free neural induction system to differentiate hESCs into MSN-like neurons. The same year, another group published results suggesting high yield differentiation of hESC derivatives into DARPP32+ neurons that survived as long as 6 months after grafting into an unlesioned striatum of young nude rats [72].

Altogether, these results demonstrated that hPSC-derived striatal differentiation is possible, but they are not reliable enough yet to generate safe therapeutically relevant cell therapy products for HD. Efforts are currently focused on improving this.

\section{Quality Control and Good Clinical and Manufacturing Practices for HD Stem Cell Therapy}

Comparing clinical trials on neurodegenerative diseases is not an easy task, in particular when cell therapy is concerned. Several reviews have summarized the demographics, technical aspects, and adverse effects of recent HD transplants that concern at least 6 different teams and 27 HD patients in total [73]. Focusing on the graft preparation only by no means simplifies the comparison 


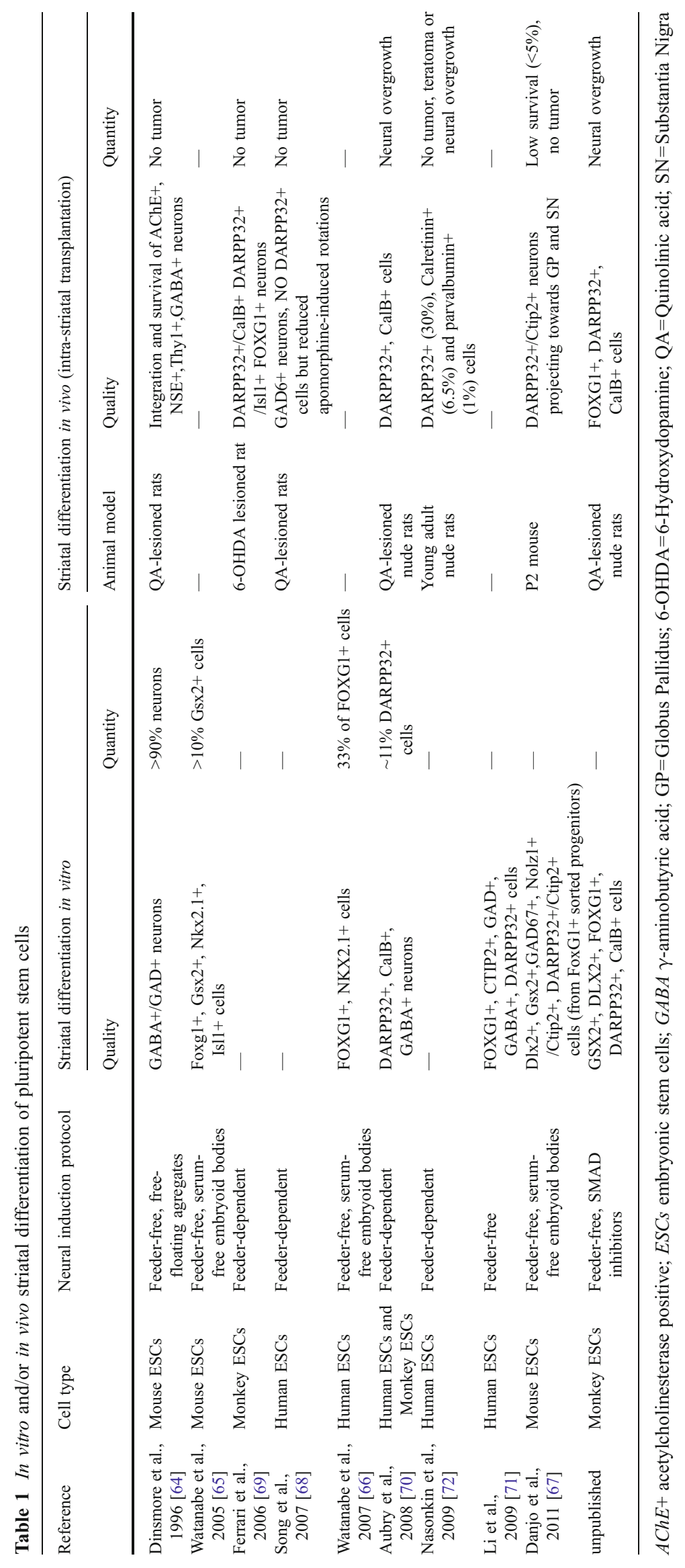


between trials due to the heterogeneity in age of donor fetuses (from 7 to 12 weeks postconception), dissection techniques, and goals ("far lateral ganglionic eminence" or "whole ganglionic eminences"), tissue preparation (cells suspension or solid preparations), and stereotaxic procedures of injection (4 to 9 tracks of 16 to $120 \mu$ leach in the caudate and/or putamen). To these plain technical variations must be added less tangible variations in the laboratory's empirical experiences with all aspects of the transplantation. Good clinical practices and good manufacturing practices (GMPs) indeed require not only the use of optimized procedures, but also strong experimental experience which guarantees the accuracy and reproducibility of each step before proceeding to the clinic.

The main challenge for quality control (QC) of fetal grafts is the accuracy of the dissection (in HD clinical trials), either of the whole ganglionic eminences, the LGE, or the far lateral ganglionic eminences, the most lateral half of the LGE. In each cases, the primary focus is on the harvest of tissue that would yield the most DARPP32+ neurons and striatal like tissue (P-zone, i.e., the $\mathrm{LGE} /$ far lateral ganglionic eminences) $[7,16,22,74-76]$. In addition, a secondary focus is on the complementary harvest of tissue to enhance the survival of LGE-derived MSNs or on the restoration of all striatal cell type, as with the harvest of whole GE $[6,8,77]$. In practice, inappropriate dissection of tissue may happen in particular (but not exclusively) when the integrity of the head of the terminated fetus is not preserved. This has been reported, in particular, when transplanted patients showed intra-striatal development of a liquid cyst likely derived from contamination by choroid plexus tissue in Parkinson's disease patients $[78,79]$. In other cases, the graft was rather contaminated by unknown, non-neural tissue, the subsequent growth of which led to overgrowth and even death [80].

A second challenge for QC of fetal grafts is the limited amount of tests that can actually be conducted to guarantee the sanitary/safety status of the preparation. Here, the 2 key issues are lack of time and the uniqueness of each fetal preparation. Serological tests are conducted on the mother approximately 1 week prior to the abortion. These tests control a possible infection by major threatening viruses (human immunodeficiency virus [HIV]1, 2, human Tlymphotropic virus 1,2 , hepatitis $\mathrm{B}$ virus, hepatitis $\mathrm{C}$ virus and so forth), although it is not established whether the fetal brain tissues can indeed be infected this early during gestation from the mother. Before transplantation, no sanitary control of the final fetal preparation ready to be grafted can be performed to test potential viral or bacterial infections, or contamination with endotoxins. Discussed as follows in more detail, human leukocyte antigens (HLAs) are not typed. In the particular context of fetal cell therapy, the surgeons are never offered the choice between several fetal preparations (e.g., with one being immunologically more compatible than the others). Finally, genomic integrity of the fetus is also not tested also lack of time. This is less of a concern than for PSC (see section as follows on "Safety of Neural Cell Therapy"), because in the context of fetal grafts, major chromosomal defects that would most likely lead to cell death and elimination after transplantation would be sought here rather than potential oncogenicity, implying a lethal threat to the patient.

hPSC-derived grafts for HD cell therapy, again constitute an entirely different paradigm than fetal-derived neural grafts with regard to quality control and good clinical practices and GMPs. Indeed, none of the major QC issues relative to fetal neural tissue is relevant to the preparation of equivalent hPSC derivatives. The only common feature is that hPSC-derived transplants will most likely be prepared as a "cell suspension," which seems to be advantageous, as it may allow better survival and better connectivity in the rat of the graft with the host pallidum [81]. It may also elicit a reduced inflammatory immune response as compared to solid transplants, due to less disruption and faster reorganization of the blood-brain barrier [82, 83], which is further discussed as follows.

The major difference between fetal and hPSC-derived neural grafts for HD is that these therapeutic products fall into 2 largely different regulatory categories. Fetal neural grafts, although they may contain "stem cells" from the neural germinative zone, are "unmodified" (i.e., they have not been grown in culture), and as such are considered within regulations of organ transplants in several European countries. On the contrary, hPSC derivatives for cell therapy, known as the "stem cells that have been extensively manipulated/modified or subject [to] an engineering process," according to the European regulations, are considered to be drugs, which in Europe falls under the European Union Tissue and Cells Directives. This implies that hPSC therapy products follow the same regulations as conventional medicinal products. Such regulations require the detailed description of the cells, of their production process, and their quality assessment (i.e., standard operating procedures). Production of clinical grade hPSC derivatives must be highly reproducible and validated. It should take place in dedicated facilities accredited with GMP for pharmaceutical manufacturers, which means at least a highly aseptic environment in which both raw materials and handlers are strictly controlled. GMPs are defined by regulatory agencies, such as the European Medicines Agencies or the United States (US) Food and Drug Administration (FDA). GMPs, in particular, include quality control and quality assurance programs that will guarantee clinic grade level for hPSCs and all procedures used for the generation, and quality control of the cells to be grafted. Each batch of hPSC derivatives must be produced with qualified reagents following standardized protocols and 
must be fully tested. Quality testing before release for clinical use are aimed at ensuring viability, sterility, and appropriate cellular composition (i.e., proportion of desired progenitors and lack of extraneous cells), and are also aimed at preventing potential microbiological and endotoxin contaminations or controlling risk of cell transformation. The very first requirement for clinical grade hPSC derivatives for HD cell therapy is the use of clinical grade PSC lines. Of the 2 types of hPSC, only hESCs exist currently as clinical grade lines. Two such lines have already been included in the US FDA-approved clinical trials; the first 1 to Geron for the treatment of spinal cord injury and the second one to Advanced Cell Technology for Stargardt's macular dystrophy and age-related macular degeneration. Geron's strategy was to qualify the research grade H1 hESC line for human use, demonstrating their normal karyotype and lack of measurable contaminants of human or animal origin. In addition, several other clinical grade hESC lines have been reported, with the first to have been generated, amplified, and banked in 2007 [84]. Clinical grade lines are inseparable from clinical grade protocols to amplify and bank these cells. In this direction, many protocols have been developed based on animal-free culture media [85, 86], GMP quality feeder [87-90], or feeder-free matrices [91].

No human iPSC line has yet been developed under GMP conditions. Original cell reprogramming techniques [14, 15] involved retrovirus- or lentivirus-mediated genomic integration of 4 reprogramming factors, 1 of which is being a potentially very active oncogene. Reprogramming technologies apparently compatible with the generation of clinical grade have since been developed. They are based on nonintegrative viruses [92, 93], plasmids [94], recombinant proteins [93, 95], or else synthetic modified mRNA [96]. A quick survey of funded research programs across the world indicates that many laboratories aim at producing such "clean" cell lines.

These challenging and costly requirements are common to all other regenerative medicine programs based on hPSC, and HD translational research will therefore benefit for the advancement of science and techniques in other indications. What will remain specific to HD cell therapy programs is the development of a clinical grade protocol for the differentiation of hPSC into the therapeutically relevant MSN cell population. As developed earlier in this review, the protocol to differentiate hPSC into striatal precursors suitable for cell therapy in HD is not yet fully determined. Therefore, it is too early to discuss its possible adaptation to GMP requirement. Nevertheless, recent publications indicate that research-grade protocols for neural differentiation of hPSC can be adapted to accommodate GMP requirements. For example, we have been able to conduct efficient neural induction protocols using SMAD inhibitors in a fully defined medium [63]. In parallel, recent work of Saisai's group has demonstrated that common patterning cytokines, such as SHH, can be substituted with relevant chemical agonists [67].

\section{Immunogenicity of Striatal Neural Grafts}

The brain has long been considered an immunologically privileged site, mostly due to the presence of the bloodbrain barrier (BBB), the absence of professional antigenpresenting cells and the limited lymphatic drainage from the central nervous system (CNS). A growing amount of evidence, however, now shows that this privilege is far from absolute. Indeed, the BBB can be seen more like a gate than a barrier, a gate that can (in particular) open during inflammation, allowing the infiltration of activated immune cells. In addition, microglial cells have the capacity for antigen presenting and lymphatic drainage, which occurs from the CNS to the cervical lymph nodes (for a detailed review see Barker and Widner [97]). In the context of HD cell therapy, during transplantation surgery, stereotaxic needles inevitably damage the BBB, creating vascular lesions and worsening the underlying local neuroinflammation caused by HD [98].

At the time that the first HD cell therapy clinical trials started, little consideration was given to the search for postgraft immune responses after transplantation of cells and tissues into the brain, which was probably due to the original notion of the immune privilege of the brain. Equally, due to the very limited availability of fetal tissue, graft/host matching is not performed in ongoing trials. Accordingly, immunosuppressive treatments both in HD and PD clinical trials have ranged from long-term tritherapy (azathioprine, cyclosporine, and prednisone) [99, $100]$ to absolutely no treatment [101] with many intermediate situations [6, 7, 102-104]. Most often, 6 to 12 months of mild immunosuppression was prescribed after transplantation to control the patients' responses long enough for their BBB to fully recover and neuroinflammation level to fall back to pre-surgery level. However, an immune reaction has been observed at least in some cases. Recent studies have shown either the presence of anti-HLAs or inflammation [22, 105-107]. Krystkowiak et al. [107] reported that as many as half of the HD patients had immunization develop against donor antigens during their phase II multi-center study of fetal neural transplants, with 1 patient showing full clinical, radiological, and biological symptoms of immune rejection. In that particular case, clinical status alteration was correlated with a decreased metabolic activity in the right striatum, accompanied by edema, as shown by magnetic resonance imaging and positron emission tomograhic scans. Immunological testing 
revealed anti-HLAs against antigens from 2 different fetuses in the blood and cerebrospinal fluid. However, in contrast with the prognosis in "classical" organ grafting, this rejection was fully reversed after aggressive antiinflammatory treatment and re-establishment of the immunosuppressive regimen. Similarly, histological analyses of several autopsied HD patients (10 years after grafting) revealed mild sustained and chronic immune response with preferential microglial infiltration around graft-derived MSN [22]. Microglial activation being correlated with an early event of HD pathogenesis [108, 109], this specific activation of microglia around genetically unrelated striatal projection neurons suggests a link between this activation and neuron degeneration. In conclusion, since the first clinical trial of HD cell therapy in the late 90 s, the vision on what is best, if any, immunotreatment should be applied has unquestionably changed. It is nonetheless still debated whether host immune reaction to grafted tissues is a problem that can easily be controlled with proper immunosuppression, or whether it is a major issue, possibly responsible for many negative clinical and functional results observed after grafting, notably in patients with Parkinson's disease as hypothesized in 1 study [103].

The use of human pluripotent stem cell derivatives as an alternative source to fetal tissue for neurodegenerative disease allows immunological issues to be addressed in many additional ways. First, while 2 categories of fetal-derived grafts exist, and that is, 1) "suspension" and 2) "solid", the hPSC-derived transplants for HD fall by definition in the first category. Although unrelated to the origin of the hPSCderived graft, this aspect is not trivial with regard to immunological issues, as immune responses are lower in cell suspensions than in solid fetal grafts [82, 103, 110, 111].

Since 2007, Yamanaka's and Thomson's seminal publications on human iPSC derivation [15, 112], and although the first clinical grade patient-specific iPSC line is yet to be reported, the most common answer to the immunologically ideal type of cell therapy is "patient-specific iPSC." The obvious reason for this is that a transplant derived from patient-specifc iPSCs, and then the patient would be perfectly isogenic, and consequently should raise no immunological barriers to the transplant. Although this ideal scheme is most likely generally true, at least 2 objections can be raised to help reconsider the possibility of at least mild isogenic immune responses. First, patientspecific iPSC derivatives can present improper (xeno or aberrant) immunologic antigens as a result of culture in animal product-containing media [113] or nonphysiologic media $[114,115]$, or else due to genomic alteration [116118] or incomplete/inappropriate epigenome reprogramming (e.g., epigenetic memory of the somatic cell reprogrammed) [119]. Second, due to their accelerated in vitro differentiation, patient-iPSC derivatives could be immuno- logically immature. This would then result in the abnormal presentation of residual embryonic/fetal antigens that may not be recognized as "self" by an adult immune system, or to improper production of ligands that are essential for immune inhibition. Nevertheless, these problems can probably be solved using the appropriate GMP standards and QC procedures previously discussed, including chemically defined media (animal free), control of genomic alterations using molecular karyotyping, use of nonintegrative reprogramming protocols, and control, as much as possible for the abnormal presentation of antigens.

More important is the fact that in the context of HD cell therapy, as in other degenerative disorders of genetic origin, the choice of a patient-specific iPSC line, as an immunologically perfect substitute to fetal neural cells, is not as inconsequential. In a genetic disease, it is far from ideal to consider using cells carrying the same mutation that causes neurons to degenerate. Although still hypothetical, it is very likely that graft-derived neurons would then be as sensitive as host cells to cell autonomous (e.g., HD mutation in the cells) or noncell autonomous signals (e.g., HD pathology in the host brain) that cause neurodegeneration. Cicchetti et al. [22] have reported that even "young" genetically unaffected projection neurons that were grafted in an HD patient may degenerate. In parallel, several reports have highlighted the possibility of disease transmission in the Parkinson's disease patient brain to the initially healthy graft $[120,121]$. As a consequence, HD patient-specific iPSC would have to be genetically corrected, which would add considerable complications, both technical and regulatory, to their use for cell therapy in the clinic.

Besides any scientific consideration as to the patientspecific iPSC for cell therapy, pragmatic and economical reasons may be considered as well. It is far from clear that the timely generation of a personal clinical grade iPSC line and the corresponding quality controlled striatal graft needed for each HD patient to be transplanted would ever be economically sustainable. A more pragmatic alternative may be the construction of iPSC banks containing homozygous HLA haplotyped cell lines [122]. These lines would present the most common HLA haplotypes in the local population and may then prove to be a sustainable alternative, provided that the percentage of the population covered would be relevant. At least 1 such homozygous HLA haplotyped human iPSC has been derived as a proof of principle of the feasibility of these "haplobanks" (Shinya Yamanaka, presented at the 8th International Society for Stem cell research annual meeting, June 2010, San Francisco, CA, USA). Haplobanks of cell lines would clearly need to be linked internationally to be able to benefit the largest population of patients. Preliminary analysis of the most abundant haplotypes in populations with 4 different ancestry backgrounds in the United States registries of bone marrow donors, namely 1) Caucasians, 2) 
Asians, 3) Hispanics, and 4) African Americans, revealed that only few haplotypes are shared between those ethnic groups.

As previously explained, when immunological issues are concerned, iPSC derivatives are considered to be the alternative of choice today. Human ESC derivatives, however, cannot be excluded, as demonstrated by the first PSC-based cell therapy trials accepted by the US FDA. hESCs are currently the only type of hPSC that exist as clinical grade PSC lines, and it may be many years before similar human iPSCs are made available in GMP conditions that would satisfy regulatory bodies. Another advantage of hESCs in comparison to hiPSCs is that safety issues concerning adequate reprogramming or reprogramming genes (re-)expression are of course irrelevant. For HD cell therapy, immunological data from allogenic transplantation of fetal tissue would be applicable to allogenic hESC-derived grafts, making them a viable option. Potential hESC-derived grafts would likely require no more immunosuppression than what is currently used for fetal neural grafts. It is worth mentioning, however, that 1 study [123] has shown that such a treatment may inhibit differentiation from PSC. This issue should be specifically considered before clinical implementation.

Even if further studies are required concerning the immunogenicity of PSC derivatives, especially in a brain transplantation setting, these cells hold great promise to overcome the immunological barriers presented by the clinical trials with fetal neural cells. In this field, hPSC derivatives may actually exceed the standards set by fetal grafts, although this cannot completely exclude the possibility for some form of immunosuppressive treatment to still be required at this time.

\section{Safety of Neural Cell Therapy}

As previously detailed, fetal neural grafts are intrinsically difficult to standardize and assess for quality (e.g., up to 2log variation in graft volume from donor to donor has been observed after transplantation) [124, 125]. Taking into account completed or ongoing clinical trials worldwide, the total number of $\mathrm{HD}$ patients transplanted with fetal tissue now probably reaches 100 . The number of centers in which patients have been transplanted is also large, and the number of patients grafted per center is quite variable. Reports of different types of adverse effects have been presented and can result directly from the surgical procedure, allogenic immune reactions (previously discussed), infections, or abnormalities in the grafted tissue. Cases of subdural hematoma $[7,9,106]$ and intracerebral hemorrhage [126] following transplantation of HD patients can be included in the first class. Despite the procurement of fetuses in non-GMP facilities and the possibility of contamination with vaginal flora [127], no case of infection directly attributed to the grafted tissue has been reported.

Besides surgical and immunological complications, 2 additional classes of adverse effects remain, and they can be attributed to the grafted tissue itself, namely: 1) cyst formation and 2) graft overgrowth. Both have been reported or suggested in several patients, in Parkinson's disease [78-80] and in HD [106, 126, 128]. Major cases of such complications have been discovered during a systematic neuroimaging (Magnetic Resonance Imaging (MRI), positron emission tomographic scan) follow-up post-transplantation. The autopsy analysis of the HD patient described by Keene et al. [128] showed the presence of several genuine neural grafts, but also 3 aberrant ependymal cysts and 8 mass lesions in the brain, which appeared to have been stable for 4 years at the time of death, with no remaining proliferating cells. The authors hypothesize that the graft overgrowth and cysts may have arisen, at least in part, from either an autologous peripheral nerve cograft or from co-dissected tissue around the donor ganglionic eminences. In PD, mis-dissection may additionally include choroid plexus [78] or other non-CNS tissues [111].

As previously discussed, it is clear from experimental studies in the rat and the primate that best results were obtained in terms of integration and functional recovery when still proliferating neuroblasts were grafted. Accordingly, human grafts essentially comprise neuroepithelial cells of the germinative zones, and growth of as much as several times in volume has been evaluated [2]. However, the precise differentiation stage is ill-defined and slight over-evaluation of the fetal age may produce grafting material that is underdifferentiated and over-proliferating. This, together with the inappropriate dissection previously discussed may explain the reported cases of HD graft overgrowth [126, 128].

When considering the use of pluripotent stem cellderived graft as an alternative to fetal neural tissue in the same therapeutic context, safety concerns become even more predominant, whether risks are indeed considered real or not. One illustration of this difficulty has been the onagain, off-again world first human trial of embryonic stem cell therapy triggered by successive waves of safety concerns raised by the US FDA. Regulatory agencies current chief concerns are: 1) the characterization of cell product (mixtures predictability and contamination), 2) unwanted growth and differentiation, 3) potential unpredictability of cells, 4) difficulty in monitoring cells for harmful effects or retrieving cells for such reasons, and 5) possible lack of predictability of small animal tests performed to evaluate cells (compared to animal test for small molecules). The most widely publicized safety concern as to the hPSC-derived graft is the risk of uncontrolled proliferation of the cell therapy product due to the textbook capacity of unlimited self-renewal of the parent cells. In the context of HD cell therapy, this generic 
risk of tumor formation refers to 3 distinct issues: 1) teratoma-like formation originating from leftover undifferentiated hPSC; 2) neural overgrowth generated by a range of proliferative neural or even striatal progenitors that have preserved important, yet physiological proliferative capacity; and 3) neoplasic tumor that could originate from transformed PSC derivatives, carrying an abnormal karyotype.

A teratoma refers to an encapsulated tumor with tissue components characteristic of derivatives of the 3 germ layers. Teratomas are dangerous, both because they can generate cancer growths (although infrequently), which are called teratocarcinomas, and because their volume increases as benign tumors, which is much more dangerous when it occurs in the brain than elsewhere in the body. They are usually thought to be derived from undifferentiated PSCs emerging from abnormally fertilized ovocytes, and can occur in patients of all ages. In the context of PSC-based cell therapy, teratomas can form if the grafted cell suspension comprises undifferentiated cells at the pluripotent stage. When at least some degree of differentiation is applied to hPSC before transplantation, teratoma-like mass may only contain derivatives from 1 or 2 , but not all germ layers [129]. In what concerns hPSC-derivatives safety, it actually seems admitted now that teratomas are not a major problem in HD cell therapy, as cells maintaining pluripotency have not been observed following long-term neural differentiation, as required to reach the relevant striatal progenitor stage [70]. Likewise, Geron demonstrated to the FDA that a contamination of less than $5 \%$ of undifferentiated $\mathrm{hESC}$ in a 2 million cell transplant did not produce teratoma 12 months after transplantation in the rat.
Of greater concern is the over-proliferation of the specifically differentiated neural progenitors. As previously discussed, for fetal GE neural grafts, the proliferative capacity of GE cells is the expression of a physiological potential consistent with the necessity for a millimeter-wide germinative zone to build up a nucleus of several cubic centimeters in the adult brain. Such an expansion capacity was problematic in the rodent xenograft experimental setting, given the obvious difference in size of the human brain and the rat brain. This, however, may not be as critical in allograft settings. Differentiation of hPSCs goes through several stages, which loosely resemble brain ontogeny. Both neuroectodermic progenitors (rosette neural stem cells [R-NSCs]) and ventral forebrain progenitors have massive proliferation potential, although the unbiased observation of the expression of this potential in vitro or in vivo is not simple. Xenografts of pure human R-NSC in rats create a concentrated and self-renewing population of cells that can generate in a few months neural grafts much bigger than the adult rat striatum itself, starting from only a few hundred thousand grafted cells. This behavior of the graft, of course, is not compatible with experimental cell therapy testing. However, longer term transplantation indicates that this overgrowth may not be indefinite, as Ki67 expression revealing proliferative cells is progressively lost, and MAP2, a post-mitotic neuronal marker, is expressed in pure R-NSC-graft 6 months post-transplantation [70].

Further evaluation of R-NSC-derived cultures enriched in ventral forebrain cells may also require cell sorting strategies. In vitro differentiation of this population yields neural progenitors reminiscent of the LGE and ultimately MSN-

Table 2 Pros (+) and Cons (-) of fetal and pluripotent stem cells-derived graft for Huntington's disease cell therapy

\begin{tabular}{|c|c|c|}
\hline Graft origin & Human fetal tissues & Human pluripotent stem cells \\
\hline \multirow[t]{4}{*}{ Logistics } & (-) Limited number of fetus actually available & $(+)$ In vitro amplification of PSCs \\
\hline & (-) No in vitro amplification & $(+)$ In vitro production of graft from PSCs \\
\hline & (-) Timing of fetus availability & (-) Definitive striatal differentiation protocol still pending \\
\hline & (-) No banking possible & $(+)$ Banking \\
\hline \multirow[t]{6}{*}{ Quality Control } & (-) NO STANDARDIZATION & $(+)$ STANDARDIZATION \\
\hline & (-) No sanitary control on fetal tissue & $(+)$ GMP protocols (amplification, banking, differentiation) \\
\hline & (-) Dissection accuracy & $(+)$ True QC of PSC and graft \\
\hline & & $(+)$ Clinic-grade hESC lines available \\
\hline & & (-) No Clinic-grade hiPSC lines available yet \\
\hline & $(+)$ "Organ transplant regulations" & (-) "Drug regulations" \\
\hline \multirow[t]{2}{*}{ Immunogenicity } & (-) No MHC matching=allorejection possible & (+) Patient-derived iPSCs \\
\hline & $(+)$ Long term survival of allograft in patient & $(+)$ Haplotyped iPSCs \\
\hline \multirow[t]{2}{*}{ Safety issues } & (-) Cysts & (-) Neural overgrowth \\
\hline & (-) Overgrowth & (-) Tumor/teratoma like formation \\
\hline Therapeutic relevance & $(+)$ Demonstrated reduction of HD symptoms & (-) No data available \\
\hline
\end{tabular}

GMP good manufacturing practices; HD Huntington's disease; $h E S C$ human embryonic stem cells; $i P S C s$ induced pluripotent stem cells; MHC = ; PSCs pluripotent stem cells; $Q C$ quality control 
like neurons. In vivo they do give rise to the large numbers of MSN-like neurons, but these are mixed with large numbers of less mature neural cells. Although hPSC-derived GE-like neural cells probably have strong proliferative capacity, as their fetal equivalent, it is likely that remaining uncommitted R-NSC are present in these populations and are actually responsible for most of the overgrowth observed in vivo. Normal engraftment and functional recovery will most likely require some degree of proliferation of the hPSC equivalent of GE grafts. As a consequence, avoiding unwanted proliferation in the HD graft may be problematic. This precludes the use of preemptive measures against mitotic cells in the transplant. Management of the proliferation of hPSC derivatives will rely rather on pre-grafting QC and differentiation protocols optimally designed to reduce the risk of over-proliferation (-) associated with post-grafting capacity at "reactive" measures (to be triggered if required), aiming at stopping excessive proliferation of the grafted neural progenitors. This secondary reaction against a potential risk can take the direction of several ways, including the administration of anti-mitotic drugs with particular affinity for neural tumors. An alternative method, which takes advantage of the possibility of introducing transgenes in these cells while they grow in vitro, uses a "suicide" gene [130] that can be triggered in vivo to stop the proliferation of the grafted cells after an "appropriate" graft mass has been reached. This paradigm has already been used for gene therapy in brain cancer patients [131].

Finally, the risk of neoplasia stems from the fact that longterm cultured cells in vitro may acquire karyotypical anomalies that would give abnormal cells a proliferative advantage, leading to their enrichment in culture and subsequent carryover in mass of these potentially "pre-transformed" cells in the grafted material. In vitro, this possibility is welldocumented for undifferentiated hPSC [116-118, 132, 133] and for fetal-derived human neural progenitor cell culture in which emerging dominance of trisomic cells (chromosome 7 or 19) is correlated with increased proliferation, neurogenesis, and expression of the epidermal growth factor receptor [134, 135]. These reports advocate for careful and systematic QC of the karyotype of the hPSC derivatives using the most sensitive techniques and not just relying on usual G-banding.

Overall, addressing the multiple safety concerns of the regulatory agencies concerning the behavior of the transplanted cells and the potential lack of predictability of the small animal model will certainly call for a high degree of characterization of hPSC-derived grafting material and teratoma/overgrowth assays that may require the use of species-specific cell lines (e.g., iPSC-derived) and/or large animal testing.

In conclusion, drawing from the broader flexibility of PSC, the risks inherent to the use of these cells in a clinical setting of cell transplantation appear controllable (as summarized in Table 2). The use of these cells now have to be proven that they are a valid alternative to fetal cells for transplantation therapy in HD in terms of long-term clinical efficacy.

Acknowledgments This work was supported by the AFM (Association française contre les myopathies). C.N. and P.V. are supported by grants from NeuroStemcell (European Community's Seventh Framework Program grant agreement nr. 222943) and the French National Research Agency (TK-SAFE program nr. ANR-07-RIB-016), respectively.

Full conflict of interest disclosure is available in the electronic supplementary material for this article.

\section{References}

1. The Huntington's Disease Collaborative Research Group. A novel gene containing a trinucleotide repeat that is expanded and unstable on Huntington's disease chromosomes. Cell 1993;72:971-983.

2. Peschanski M, Cesaro P, Hantraye P. Rationale for intrastriatal grafting of striatal neuroblasts in patients with Huntington's disease. Neuroscience 1995;68:273-285.

3. Palfi S, Conde F, Riche D, et al. Fetal striatal allografts reverse cognitive deficits in a primate model of Huntington disease. Nat Med 1998;4:963-966.

4. Kendall AL, Rayment FD, Torres EM, Baker HF, Ridley RM, Dunnett SB. Functional integration of striatal allografts in a primate model of Huntington's disease. Nat Med 1998;4:727-729.

5. Bachoud-Levi A, Bourdet C, Brugieres P, et al. Safety and tolerability assessment of intrastriatal neural allografts in five patients with Huntington's disease. Exp Neurol 2000;161:194-202.

6. Bachoud-Levi AC, Remy P, Nguyen JP, et al. Motor and cognitive improvements in patients with Huntington's disease after neural transplantation. Lancet 2000;356:1975-1979.

7. Hauser RA, Furtado S, Cimino CR, et al. Bilateral human fetal striatal transplantation in Huntington's disease. Neurology 2002;58:687-695.

8. Rosser AE, Barker RA, Harrower T, et al. Unilateral transplantation of human primary fetal tissue in four patients with Huntington's disease: NEST-UK safety report ISRCTN no 36485475. J Neurol Neurosurg Psychiatry 2002;73:678-685.

9. Keene CD, Sonnen JA, Swanson PD, et al. Neural transplantation in Huntington disease: long-term grafts in two patients. Neurology 2007;68:2093-2098.

10. Reuter I, Tai YF, Pavese N, et al. Long-term clinical and positron emission tomography outcome of fetal striatal transplantation in Huntington's disease. J Neurol Neurosurg Psychiatry 2008;79:948951.

11. Bachoud-Levi AC, Gaura V, Brugieres P, et al. Effect of fetal neural transplants in patients with Huntington's disease 6 years after surgery: a long-term follow-up study. Lancet Neurol 2006;5:303-309.

12. Dunnett SB, Rosser AE. Stem cell transplantation for Huntington's disease. Exp Neurol 2007;203:279-292.

13. Thomson JA. Embryonic stem cell lines derived from human blastocysts. Science 1998;282:1145-1147.

14. Takahashi K, Tanabe K, Ohnuki M, et al. Induction of pluripotent stem cells from adult human fibroblasts by defined factors. Cell 2007;131:861-872.

15. Yu J, Vodyanik MA, Smuga-Otto K, et al. Induced pluripotent stem cell lines derived from human somatic cells. Science 2007;318:1917-1920.

16. Grasbon-Frodl EM, Nakao N, Lindvall O, Brundin P. Phenotypic development of the human embryonic striatal primordium: a study of cultured and grafted neurons from the lateral and medial ganglionic eminences. Neuroscience 1996;73:171-183. 
17. Naimi S, Jeny R, Hantraye P, Peschanski M, Riche D. Ontogeny of human striatal DARPP-32 neurons in fetuses and following xenografting to the adult rat brain. Exp Neurol 1996;137:15-25.

18. Wictorin K. Anatomy and connectivity of intrastriatal striatal transplants. Prog Neurobiol 1992;38:611-639.

19. Dunnett SB. Functional analysis of fronto-striatal reconstruction by striatal grafts. Novartis Found Symp 2000;231:21-52.

20. Dunnett SB, Meldrum A, Muir JL. Frontal-striatal disconnection disrupts cognitive performance of the frontal-type in the rat. Neuroscience 2005;135:1055-1065.

21. Freeman TB, Hauser RA, Willing AE, Zigova T, Sanberg PR, Saporta S. Transplantation of human fetal striatal tissue in Huntington's disease: rationale for clinical studies. Novartis Found Symp 2000;231:129-47.

22. Cicchetti F, Saporta S, Hauser RA, et al. Neural transplants in patients with Huntington's disease undergo disease-like neuronal degeneration. Proc Natl Acad Sci USA 2009;106:12483-12488.

23. Eriksson C, Bjorklund A, Wictorin K. Neuronal differentiation following transplantation of expanded mouse neurosphere cultures derived from different embryonic forebrain regions. Exp Neurol 2003;184:615-635.

24. Fricker-Gates RA, Winkler C, Kirik D, Rosenblad C, Carpenter MK, Bjorklund A. EGF infusion stimulates the proliferation and migration of embryonic progenitor cells transplanted in the adult rat striatum. Exp Neurol 2000;165:237-247.

25. Svendsen CN, Clarke DJ, Rosser AE, Dunnett SB. Survival and differentiation of rat and human epidermal growth factorresponsive precursor cells following grafting into the lesioned adult central nervous system. Exp Neurol 1996;137:376-388.

26. Visnyei K, Tatsukawa KJ, Erickson RI, et al. Neural progenitor implantation restores metabolic deficits in the brain following striatal quinolinic acid lesion. Exp Neurol 2006;197:465-474.

27. Mukhida K, Mendez I, McLeod M, et al. Spinal GABAergic transplants attenuate mechanical allodynia in a rat model of neuropathic pain. Stem Cells 2007;25:2874-2885.

28. Armstrong RJ, Watts C, Svendsen CN, Dunnett SB, Rosser AE. Survival, neuronal differentiation, and fiber outgrowth of propagated human neural precursor grafts in an animal model of Huntington's disease. Cell Transplant 2000;9:55-64.

29. El Akabawy G, Martinez-Medina L, Jeffries AR, Price J, Modo M. Purmorphamine increases DARPP-32 differentiation in human striatal neural stem cells through the hedgehog pathway. Stem Cells Dev [serial online] 2011; Available at: www. liebertonline.com/scd. Accessed September 15, 2011.

30. Mizuseki K, Kishi M, Matsui M, Nakanishi S, Sasai Y. Xenopus Zic-related-1 and Sox-2, two factors induced by chordin, have distinct activities in the initiation of neural induction. Development 1998;125:579-587.

31. Rex M, Orme A, Uwanogho D, et al. Dynamic expression of chicken Sox 2 and Sox 3 genes in ectoderm induced to form neural tissue. Dev Dyn 1997;209:323-332.

32. Sheng G, dos Reis M, Stern CD. Churchill, a zinc finger transcriptional activator, regulates the transition between gastrulation and neurulation. Cell 2003;115:603-613.

33. Zhang X, Huang CT, Chen J, et al. Pax6 is a human neuroectoderm cell fate determinant. Cell Stem Cell 2010;7:90-100.

34. Tao W, Lai E. Telencephalon-restricted expression of BF-1, a new member of the HNF-3/fork head gene family, in the developing rat brain. Neuron 1992;8:957-966.

35. Shimamura K, Rubenstein JL. Inductive interactions direct early regionalization of the mouse forebrain. Development 1997;124:2709-2718.

36. Muzio L, Mallamaci A. Emx1, emx2 and pax6 in specification, regionalization and arealization of the cerebral cortex. Cereb Cortex 2003;13:641-647.
37. Anderson SA, Qiu M, Bulfone A, et al. Mutations of the homeobox genes Dlx-1 and Dlx-2 disrupt the striatal subventricular zone and differentiation of late born striatal neurons. Neuron 1997;19:27-37.

38. Corbin JG, Gaiano N, Machold RP, Langston A, Fishell G. The Gsh2 homeodomain gene controls multiple aspects of telencephalic development. Development 2000;127:5007-5020.

39. Toresson H, Parmar M, Campbell K. Expression of Meis and $\mathrm{Pbx}$ genes and their protein products in the developing telencephalon: implications for regional differentiation. Mech Dev 2000;94:183-187.

40. Szucsik JC, Witte DP, Li H, Pixley SK, Small KM, Potter SS. Altered forebrain and hindbrain development in mice mutant for the Gsh-2 homeobox gene. Dev Biol 1997;191:230-242.

41. Jain M, Armstrong RJ, Barker RA, Rosser AE. Cellular and molecular aspects of striatal development. Brain Res Bull 2001;55:533-540.

42. Deacon TW, Pakzaban P, Isacson O. The lateral ganglionic eminence is the origin of cells committed to striatal phenotypes: neural transplantation and developmental evidence. Brain Res 1994;668:211-219.

43. Campbell K, Olsson M, Bjorklund A. Regional incorporation and site-specific differentiation of striatal precursors transplanted to the embryonic forebrain ventricle. Neuron 1995;15:1259-1273.

44. Walaas SI, Greengard P. DARPP-32, a dopamine- and adenosine 3':5'-monophosphate-regulated phosphoprotein enriched in dopamine-innervated brain regions. I. Regional and cellular distribution in the rat brain. J Neurosci 1984;4:84-98.

45. Ouimet CC, Greengard P. Distribution of DARPP-32 in the basal ganglia: an electron microscopic study. J Neurocytol 1990;19:39-52.

46. Arlotta P, Molyneaux BJ, Jabaudon D, Yoshida Y, Macklis JD. Ctip2 controls the differentiation of medium spiny neurons and the establishment of the cellular architecture of the striatum. J Neurosci 2008;28:622-632.

47. Ferland RJ, Cherry TJ, Preware PO, Morrisey EE, Walsh CA. Characterization of Foxp2 and Foxp1 mRNA and protein in the developing and mature brain. J Comp Neurol 2003;460:266-279.

48. Tamura S, Morikawa Y, Iwanishi H, Hisaoka T, Senba E. Foxp1 gene expression in projection neurons of the mouse striatum. Neuroscience 2004;124:261-267.

49. Rakic P. Evolution of the neocortex: a perspective from developmental biology. Nat Rev Neurosci 2009;10:724-735.

50. Zhang SC, Wernig M, Duncan ID, Brustle O, Thomson JA. In vitro differentiation of transplantable neural precursors from human embryonic stem cells. Nat Biotechnol 2001;19:1129-1133.

51. Carpenter MK, Inokuma MS, Denham J, Mujtaba T, Chiu CP, Rao MS. Enrichment of neurons and neural precursors from human embryonic stem cells. Exp Neurol 2001;172:383-397.

52. Reubinoff BE, Itsykson $\mathrm{P}$, Turetsky $\mathrm{T}$, et al. Neural progenitors from human embryonic stem cells. Nat Biotechnol 2001;19:1134-1140.

53. Rathjen J, Rathjen PD. Formation of neural precursor cell populations by differentiation of embryonic stem cells in vitro. ScientificWorldJournal 2002;2:690-700.

54. Perrier AL, Tabar V, Barberi T, et al. Derivation of midbrain dopamine neurons from human embryonic stem cells. Proc Natl Acad Sci USA 2004;101:12543-12548.

55. Kawasaki H, Mizuseki K, Sasai Y. Selective neural induction from ES cells by stromal cell-derived inducing activity and its potential therapeutic application in Parkinson's disease. Methods Mol Biol 2002;185:217-227.

56. Kawasaki H, Suemori H, Mizuseki K, et al. Generation of dopaminergic neurons and pigmented epithelia from primate ES cells by stromal cell-derived inducing activity. Proc Natl Acad Sci USA 2002;99:1580-1585. 
57. Cibelli JB, Grant KA, Chapman KB, et al. Parthenogenetic stem cells in nonhuman primates. Science 2002;295:819.

58. Ying QL, Stavridis M, Griffiths D, Li M, Smith A. Conversion of embryonic stem cells into neuroectodermal precursors in adherent monoculture. Nat Biotechnol 2003;21:183-186.

59. Lee H, Al Shamy G, Elkabetz Y, et al. Directed Differentiation And Transplantation of Human Embryonic Stem Cell Derived Motoneurons. Stem Cells 2007;25:1931-1939.

60. Sonntag KC, Pruszak J, Yoshizaki T, van Arensbergen J, Sanchez-Pernaute R, Isacson O. Enhanced yield of neuroepithelial precursors and midbrain-like dopaminergic neurons from human embryonic stem cells using the bone morphogenic protein antagonist noggin. Stem Cells 2007;25:411-418.

61. Elkabetz Y, Panagiotakos G, Al Shamy G, Socci ND, Tabar V, Studer L. Human ES cell-derived neural rosettes reveal a functionally distinct early neural stem cell stage. Genes Dev 2008;22:152-165.

62. Chambers SM, Fasano CA, Papapetrou EP, Tomishima M, Sadelain M, Studer L. Highly efficient neural conversion of human ES and iPS cells by dual inhibition of SMAD signaling. Nat Biotechnol 2009;27:275-280.

63. Benchoua A, Aubry L, Perrier A, et al. Method and medium for neural differentiation of pluripotent cells. 2008;10.06.2010.

64. Dinsmore J, Ratliff J, Deacon T, et al. Embryonic stem cells differentiated in vitro as a novel source of cells for transplantation. Cell Transplant 1996;5:131-143.

65. Watanabe K, Kamiya D, Nishiyama A, et al. Directed differentiation of telencephalic precursors from embryonic stem cells. Nat Neurosci 2005;8:288-296.

66. Watanabe K, Ueno M, Kamiya D, et al. A ROCK inhibitor permits survival of dissociated human embryonic stem cells. Nat Biotechnol 2007;25:681-686.

67. Danjo T, Eiraku M, Muguruma K, et al. Subregional specification of embryonic stem cell-derived ventral telencephalic tissues by timed and combinatory treatment with extrinsic signals. J Neurosci 2011;31:1919-1933.

68. Song J, Lee ST, Kang W, et al. Human embryonic stem cellderived neural precursor transplants attenuate apomorphineinduced rotational behavior in rats with unilateral quinolinic acid lesions. Neurosci Lett 2007;423:58-61.

69. Ferrari D, Sanchez-Pernaute R, Lee H, Studer L, Isacson O. Transplanted dopamine neurons derived from primate ES cells preferentially innervate DARPP-32 striatal progenitors within the graft. Eur J Neurosci 2006;24:1885-1896.

70. Aubry L, Bugi A, Lefort N, Rousseau F, Peschanski M, Perrier AL. Striatal progenitors derived from human ES cells mature into DARPP32 neurons in vitro and in quinolinic acid-lesioned rats. Proc Natl Acad Sci USA 2008;105:16707-16712.

71. Li XJ, Zhang X, Johnson MA, Wang ZB, Lavaute T, Zhang SC. Coordination of sonic hedgehog and Wnt signaling determines ventral and dorsal telencephalic neuron types from human embryonic stem cells. Development 2009;136:4055-4063.

72. Nasonkin I, Mahairaki V, Xu L, et al. Long-term, stable differentiation of human embryonic stem cell-derived neural precursors grafted into the adult mammalian neostriatum. Stem Cells 2009;27:2414-2426.

73. Freeman TB, Cicchetti F, Bachoud-Levi AC, Dunnett SB. Technical factors that influence neural transplant safety in Huntington's disease. Exp Neurol 2011;227:1-9.

74. Olsson M, Campbell K, Wictorin K, Bjorklund A. Projection neurons in fetal striatal transplants are predominantly derived from the lateral ganglionic eminence. Neuroscience 1995;69:1169-1182.

75. Pakzaban P, Deacon TW, Burns LH, Isacson O. Increased proportion of acetylcholinesterase-rich zones and improved morphological integration in host striatum of fetal grafts derived from the lateral but not the medial ganglionic eminence. Exp Brain Res 1993;97:13-22.
76. Freeman TB, Cicchetti F, Hauser RA, et al. Transplanted fetal striatum in Huntington's disease: phenotypic development and lack of pathology. Proc Natl Acad Sci USA 2000;97:13877-13882.

77. Grasbon-Frodl EM, Nakao N, Lindvall O, Brundin P. Developmental features of human striatal tissue transplanted in a rat model of Huntington's disease. Neurobiol Dis 1997;3:299-311.

78. Mamelak AN, Eggerding FA, Oh DS, et al. Fatal cyst formation after fetal mesencephalic allograft transplant for Parkinson's disease. J Neurosurg 1998;89:592-598.

79. Freeman TB, Hauser RA, Sanberg PR. Fatal transplant cyst. J Neurosurg 1999;90:1148-1150.

80. Folkerth RD, Durso R. Survival and proliferation of nonneural tissues, with obstruction of cerebral ventricles, in a parkinsonian patient treated with fetal allografts. Neurology 1996;46:1219-1225.

81. Watts C, Brasted PJ, Dunnett SB. Embryonic donor age and dissection influences striatal graft development and functional integration in a rodent model of Huntington's disease. Exp Neurol 2000;163:85-97.

82. Brundin P, Widner H, Nilsson OG, Strecker RE, Bjorklund A. Intracerebral xenografts of dopamine neurons: the role of immunosuppression and the blood-brain barrier. Exp Brain Res 1989;75:195-207.

83. Rosenstein JM. Neocortical transplants in the mammalian brain lack a blood-brain barrier to macromolecules. Science 1987;235:772-774.

84. Crook JM, Peura TT, Kravets L, et al. The generation of six clinical-grade human embryonic stem cell lines. Cell Stem Cell 2007;1:490-494.

85. Li Y, Powell S, Brunette E, Lebkowski J, Mandalam R. Expansion of human embryonic stem cells in defined serumfree medium devoid of animal-derived products. Biotechnol Bioeng 2005;91:688-698.

86. Tecirlioglu RT, Nguyen L, Koh K, Trounson AO, Michalska AE. Derivation and maintenance of human embryonic stem cell line on human adult skin fibroblast feeder cells in serum replacement medium. In Vitro Cell Dev Biol Anim 46:231-235.

87. Richards M, Fong CY, Chan WK, Wong PC, Bongso A. Human feeders support prolonged undifferentiated growth of human inner cell masses and embryonic stem cells. Nat Biotechnol 2002;20:933-936.

88. Sidhu KS, Lie KH, Tuch BE. Transgenic human fetal fibroblasts as feeder layer for human embryonic stem cell lineage selection. Stem Cells Dev 2006;15:741-747.

89. Stacey GN, Cobo F, Nieto A, Talavera P, Healy L, Concha A. The development of 'feeder' cells for the preparation of clinical grade $\mathrm{hES}$ cell lines: challenges and solutions. J Biotechnol 2006;125:583-588.

90. Tsutsui H, Valamehr B, Hindoyan A, et al. An optimized small molecule inhibitor cocktail supports long-term maintenance of human embryonic stem cells. Nat Commun [serial online] 2010;2:167. Available at: www.nature.com/ncomms. Accessed September 15, 2011.

91. Klimanskaya I, Chung Y, Meisner L, Johnson J, West MD, Lanza R. Human embryonic stem cells derived without feeder cells. Lancet 2005;365:1636-1641.

92. Stadtfeld M, Nagaya M, Utikal J, Weir G, Hochedlinger K. Induced pluripotent stem cells generated without viral integration. Science 2008;322:945-949.

93. Zhou H, Wu S, Joo JY, et al. Generation of induced pluripotent stem cells using recombinant proteins. Cell Stem Cell 2009;4:381-384.

94. Okita K, Nakagawa M, Hyenjong H, Ichisaka T, Yamanaka S. Generation of mouse induced pluripotent stem cells without viral vectors. Science 2008;322:949-953.

95. Kim D, Kim CH, Moon JI, et al. Generation of human induced pluripotent stem cells by direct delivery of reprogramming proteins. Cell Stem Cell 2009;4:472-476.

96. Warren L, Manos PD, Ahfeldt T, et al. Highly efficient reprogramming to pluripotency and directed differentiation of human cells with synthetic modified mRNA. Cell Stem Cell 2010;7:618-630. 
97. Barker RA, Widner H. Immune problems in central nervous system cell therapy. NeuroRx 2004;1:472-481.

98. Silvestroni A, Faull RL, Strand AD, Moller T. Distinct neuroinflammatory profile in post-mortem human Huntington's disease. Neuroreport 2009;20:1098-1103.

99. Lindvall O, Sawle G, Widner H, et al. Evidence for long-term survival and function of dopaminergic grafts in progressive Parkinson's disease. Ann Neurol 1994;35:172-180.

100. Widner $\mathrm{H}$, Tetrud J, Rehncrona S, et al. Bilateral fetal mesencephalic grafting in two patients with parkinsonism induced by 1-methyl-4-phenyl-1,2,3,6-tetrahydropyridine (MPTP). N Engl J Med 1992;327:1556-1563.

101. Freed CR, Greene PE, Breeze RE, et al. Transplantation of embryonic dopamine neurons for severe Parkinson's disease. $\mathrm{N}$ Engl J Med 2001;344:710-719.

102. Defer GL, Geny C, Ricolfi F, et al. Long-term outcome of unilaterally transplanted parkinsonian patients. I. Clinical approach. Brain 1996;119(pt 1):41-50.

103. Olanow CW, Goetz CG, Kordower JH, et al. A double-blind controlled trial of bilateral fetal nigral transplantation in Parkinson's disease. Ann Neurol 2003;54:403-414.

104. Freeman TB, Olanow CW, Hauser RA, et al. Bilateral fetal nigral transplantation into the postcommissural putamen in Parkinson's disease. Ann Neurol 1995;38:379-388.

105. Capetian P, Knoth R, Maciaczyk J, et al. Histological findings on fetal striatal grafts in a Huntington's disease patient early after transplantation. Neuroscience 2009;160:661-675 d.

106. Gallina P, Paganini M, Di Rita A, et al. Human fetal striatal transplantation in huntington's disease: a refinement of the stereotactic procedure. Stereotact Funct Neurosurg 2008;86:308-313.

107. Krystkowiak P, Gaura V, Labalette M, et al. Alloimmunisation to donor antigens and immune rejection following foetal neural grafts to the brain in patients with Huntington's disease. PLoS ONE 2007;2:e166.

108. Tai YF, Pavese N, Gerhard A, et al. Microglial activation in presymptomatic Huntington's disease gene carriers. Brain 2007;130:1759-1766.

109. Pavese N, Politis M, Tai YF, et al. Cortical dopamine dysfunction in symptomatic and premanifest Huntington's disease gene carriers. Neurobiol Dis 37:356-361.

110. Brundin P, Bjorklund A, Lindvall O. Practical aspects of the use of human fetal brain tissue for intracerebral grafting. Prog Brain Res 1990;82:707-714.

111. Kordower JH, Goetz CG, Freeman TB, Olanow CW. Dopaminergic transplants in patients with Parkinson's disease: neuroanatomical correlates of clinical recovery. Exp Neurol 1997;144:41-46.

112. Takahashi K, Yamanaka S. Induction of pluripotent stem cells from mouse embryonic and adult fibroblast cultures by defined factors. Cell 2006;126:663-676.

113. Martin MJ, Muotri A, Gage F, Varki A. Human embryonic stem cells express an immunogenic nonhuman sialic acid. Nat Med 2005;11:228-232.

114. Chung TL, Turner JP, Thaker NY, et al. Ascorbate promotes epigenetic activation of CD30 in human embryonic stem cells. Stem Cells 2010;28:1782-1793.

115. Prowse AB, Doran MR, Cooper-White JJ, et al. Long term culture of human embryonic stem cells on recombinant vitronectin in ascorbate free media. Biomaterials 2010;31:8281-8288.

116. Draper JS, Smith K, Gokhale P, et al. Recurrent gain of chromosomes $17 \mathrm{q}$ and 12 in cultured human embryonic stem cells. Nat Biotechnol 2004;22:53-54.

117. Lefort N, Feyeux M, Bas C, et al. Human embryonic stem cells reveal recurrent genomic instability at $20 \mathrm{q} 11.21$. Nat Biotechnol 2008;26:1364-1366.
118. Spits C, Mateizel I, Geens M, et al. Recurrent chromosomal abnormalities in human embryonic stem cells. Nat Biotechnol 2008;26:1361-1363.

119. Kim K, Doi A, Wen B, et al. Epigenetic memory in induced pluripotent stem cells. Nature 2010;467:285-290.

120. Kordower JH, Chu Y, Hauser RA, Freeman TB, Olanow CW. Lewy body-like pathology in long-term embryonic nigral transplants in Parkinson's disease. Nat Med 2008;14:504-506.

121. Li JY, Englund E, Holton JL, et al. Lewy bodies in grafted neurons in subjects with Parkinson's disease suggest host-to-graft disease propagation. Nat Med 2008;14:501-503.

122. Taylor CJ, Bolton EM, Pocock S, Sharples LD, Pedersen RA, Bradley JA. Banking on human embryonic stem cells: estimating the number of donor cell lines needed for HLA matching. Lancet 2005;366:2019-2025.

123. Preynat-Seauve O, de Rham C, Tirefort D, Ferrari-Lacraz S, Krause KH, Villard J. Neural progenitors derived from human embryonic stem cells are targeted by allogeneic $\mathrm{T}$ and natural killer cells. J Cell Mol Med 2009;13:3556-3569.

124. Brundin P, Karlsson J, Emgard M, et al. Improving the survival of grafted dopaminergic neurons: a review over current approaches. Cell Transplant 2000;9:179-195.

125. Kordower JH, Rosenstein JM, Collier TJ, et al. Functional fetal nigral grafts in a patient with Parkinson's disease: chemoanatomic, ultrastructural, and metabolic studies. J Comp Neurol 1996;370:203-230.

126. Gallina P, Paganini M, Lombardini L, et al. Human striatal neuroblasts develop and build a striatal-like structure into the brain of Huntington's disease patients after transplantation. Exp Neurol 2010;222:30-41.

127. Nauert GM, Freeman TB. Low-pressure aspiration abortion for obtaining embryonic and early gestational fetal tissue for research purposes. Cell Transplant 1994;3:147-151.

128. Keene CD, Chang RC, Leverenz JB, et al. A patient with Huntington's disease and long-surviving fetal neural transplants that developed mass lesions. Acta Neuropathol 2009;117:329338.

129. Seminatore C, Polentes J, Ellman D, et al. The postischemic environment differentially impacts teratoma or tumor formation after transplantation of human embryonic stem cell-derived neural progenitors. Stroke 2010;41:153-159.

130. Moolten FL, Wells JM, Heyman RA, Evans RM. Lymphoma regression induced by ganciclovir in mice bearing a herpes thymidine kinase transgene. Hum Gene Ther 1990;1:125-134.

131. Klatzmann D, Valery CA, Bensimon G, et al. A phase I/II study of herpes simplex virus type 1 thymidine kinase "suicide" gene therapy for recurrent glioblastoma. Study Group on Gene Therapy for Glioblastoma. Hum Gene Ther 1998;9:2595-2604.

132. Werbowetski-Ogilvie TE, Bosse M, Stewart M, et al. Characterization of human embryonic stem cells with features of neoplastic progression. Nat Biotechnol 2009;27:91-97.

133. Laurent LC, Ulitsky I, Slavin I, et al. Dynamic changes in the copy number of pluripotency and cell proliferation genes in human ESCs and iPSCs during reprogramming and time in culture. Cell Stem Cell 2011;8:106-118.

134. Sareen D, McMillan E, Ebert AD, et al. Chromosome 7 and 19 trisomy in cultured human neural progenitor cells. PLoS One 2009;4:e7630.

135. Wu W, He Q, Li X, et al. Long-term Cultured Human Neural Stem Cells Undergo Spontaneous Transformation to TumorInitiating Cells. Int J Biol Sci 2011;7:892-901.

136. Zhao Y, Sheng HZ, Amini R, et al. Control of hippocampal morphogenesis and neuronal differentiation by the LIM homeobox gene Lhx5. Science 1999;284:1155-1158. 